\title{
Effects of Dietary Sanguinarine on Growth Performance, Relative Organ Weight, Cecal Microflora, Serum Cholesterol Level and Meat Quality in Broiler Chickens
}

\author{
Kyung-Woo Lee, Ji-Suk Kim, Sung-Taek Oh, Chang-Won Kang and Byoung-Ki An \\ Department of Animal Science and Technology, College of Animal Bioscience and Technology, \\ Konkuk University, 120 Neungdong-ro, Gwangjin-gu, Seoul 143-701, South Korea
}

\begin{abstract}
The present study was conducted to investigate whether dietary sanguinarine (Sangrovit ${ }^{\circledR}$, SGV) could affect growth performance, relative organ weigths, gut microbiota, serum cholesterol levels, and malondialdehyde contents of leg meat in broiler chickens. A total of 840 day-old male broiler chicks (Ross breed) was randomly placed on 28 floor pens with rice straw as a bedding and subjected to one of four experimental diets; corn-soybean meal based control diet, the control diet added with avilamycin at $10 \mathrm{ppm}$ as growth promoter (AGP) and SGV at the level of 20 (SGV20) or $50 \mathrm{ppm}$ (SGV50). The final body weight (BW), daily BW gain, and feed conversion ratio (FCR) were significantly improved $(P<0.05)$ in broiler chickens fed either AGP, SGV20 or SGV50 compared with the control diet-fed chickens. Compared with the control group, relative jejunal weight was significantly lowered $(P<0.05)$ in SGV20-fed chickens and relative jejunal or ileal length was significantly increased $(P<0.05)$ in all SGV-fed chickens. Dietary SGV20, but not AGP, altered gut microbiota (especially increase in cecal lactic acid bacteria) compared with the control diet-fed chickens. Total cholesterol of broiler chickens fed on a diet containing SGV20 or SGV50 vs. the control diet was significantly reduced. Finally, the content of malondialdehyde in thigh meats as an indicator of lipid peroxidation was significantly lowered $(P<0.05)$ by dietary SGV compared with that seen in the control chickens. In conclusion, our study clearly reveals that supplementation of SGV into the broilers' diet at 20 or 50 ppm improved growth performance and altered various biological and physiological parameters such as relative organ weights, serum cholesterol levels, gut microbiota, and meat qualities in broiler chickens.
\end{abstract}

Key words: broiler chickens, growth performance, gut microbiota, meat quality, sanguinarine

J. Poult. Sci., 52: 15-22, 2015

\section{Introduction}

World population is expected to increase to more than 9 billion by the year of 2050 and agricultural sectors, specifically global poultry industry, have rapidly responded to meet the growing meat demand, which has already increased to more than 4-fold during last 4 decades (Godfray et al., 2010). In order to sustain the ever growing meat demand, it is true that the poultry production efficiency should be kept as high as possible. This statement however is based on the premises that the genetic potentials of chickens will be achieved and simultaneously any environmental challenges such as climate change, feed security, intensive production,

Received: April 30, 2014, Accepted: June 27, 2014

Released Online Advance Publication: July 25, 2014

Correspondence: BK An, Ph. D., Department of Animal Science and Technology, College of Animal Bioscience and Technology, Konkuk University, 120 Neungdong-ro, Gwangjin-gu, Seoul 143-701, Republic of Korea. (E-mail: abk7227@hanmail.net) or ban on antibiotics in poultry industry are effectively controlled (Lillehoj and Lee, 2012).

It is well understood that low-level inclusion of in-feed antibiotics as growth promoters has played a significant role in the growth and development of the poultry industry for more than 50 years. Their efficiency in stimulating growth, improving feed conversion and reducing mortality/morbidity from clinical disease is well recognized (Thomke and Elwinger, 1998). However, the consumers concerns have been raised on the drug residues in meat products and on the occurrence of drug-resistant bacteria due to frequent use of antibiotics in diets (Yang et al., 2009). As a result, the commonly practiced antibiotic inclusion into poultry diets has been banned in Europe since 2006, and this ban is further expected to affect the rest of the world. Consequently, alternative strategies to antibiotics have been mainstream of topics for researches in animal science to sustain the animal production. The most widely accepted alternatives (Lee et al., 2003; Hashemi and Davoodi, 2008; Windisch et al., 
2008; Yang et al., 2009; Grashorn, 2010) include probiotics, prebiotics, exogenous enzymes, and phytogenics including plant extracts in poultry.

Sanguinarine (SGV) as a phytogenic is a quaternary benzo [c]phenanthridine alkaloid (Dvorak and Simanek, 2007) and is an active component in the powdered stems, leaves, capsules and seeds of Macleaya cordata. With the well-established biological properties (Franz et al., 2005), it has been added into diets for bovine, swine and poultry intended to promote growth and to increase feed intake. It is known that sanguinarine possess various biological activities such as analgesic, anti-inflammatory, anti-microbial and immunomodulatory activities (Simanek et al., 2003; Dvorak et al., 2006; Niu et al., 2012). In addition, it is reported that SGV stimulates the secretion of enzymes in the intestine (Franz et al., 2005) which is often regarded as one of characteristic properties of herbs and spices (Lee et al., 2003). Furthermore, SGV is not metabolized into potentially harmful metabolite (e.g., benz[c]acridine) and is excreted without being absorbed through the small intestine (Zdarilova et al., 2008).

It has been reported that dietary SGV affected growth performance (Vieira et al., 2008a,b), cholesterol concentration (Yakhkeshi et al., 2011), fatty acid profiles of breast meats (Juskiewicz et al., 2011), and cecal microflora (Juskiewicz et al., 2011; Yakhkeshi et al., 2011) in broiler chickens and the inclusion levels in diets ranged from 12.5 to $50 \mathrm{ppm}$. It is of note that dietary sanguinarine stimulated growth at early ages of chickens (Vieira et al., 2008a, b). At this stage, the effect of SGV on meat quality in broiler chickens has not been studied albeit that there is indication on its antioxidant property (Vrba et al., 2004). In addition, the lack of sufficient number of controlled studies may preclude with confidence from concluding various reported biological properties of SGV in broiler chickens (Simanek et al., 2003). Thus, the present study was conducted to investigate whether dietary SGV could affect growth performance, relative organ weights, cecal microflora, serum cholesterol concentration, and lipid peroxidation of leg meats in broiler chickens.

\section{Materials and Methods}

\section{Experimental Design}

Eight-hundred forty day-old male broiler chicks were obtained from local hatchery. Upon arrival, they were individually weighed and randomly placed 30 chicks per pen, 7 pens per treatment. The ingredients and composition of starter and finisher diets were shown in Table 1 and used as a control diet. The control diet was formulated to meet or exceed the nutrients requirement recommended by National Research Council (NRC, 1994). In order to formulate the experimental diets, avilamycin as growth promoter at the level of $10 \mathrm{ppm}$ and two levels of SGV (Sangrovit ${ }^{\mathbb{B}}$, Phytobiotics, Eltville, Germany) at 20 (SGV20) and 50 (SGV50) ppm were added into the control diet at the expense of wheat flour. Sangrovit ${ }^{\circledR}$ is a commercial product composed of 1.5 $\%$ sanguinarine as an active component. Diet and water were provided on ad libitum basis. All experimental protocols were approved by the Animal Care Committee of KonKuk University. The temperature of facility was maintained at $32^{\circ} \mathrm{C}$ during the first week posthatch and gradually decreased to reach $25^{\circ} \mathrm{C}$ at 3 weeks.

\section{Sampling}

Feed intake per pen and individual body weight (BW) were measured on a weekly basis and used to calculate feed conversion ratio (FCR). At 5 weeks, blood was sampled from the randomly selected seven chickens per pen after cervical dislocation. Sera were obtained by gentle centrifugation and stored at $-20^{\circ} \mathrm{C}$ prior to use. Immediately after blood sampling, abdominal fat and organs such as spleen and bursa of Fabricius were excised, weighed and expressed as relative weight to $\mathrm{BW}$. In addition, leg and breast meats were sampled and weighed, and the former stored at $-20^{\circ} \mathrm{C}$ for later measurement of malondialdehyde contents. Breast meat was discarded. Whole intestine was sampled and the length and weight of each segment of small intestine were recorded. Duodenum was defined as the pancreatic loop, jejunum as the segment from the end of the duodenum to Meckel's diverticulum and ileum as the region between Meckel's diverticulum and ileocecal junction. Ceca were sampled and stored on ice until used for gut microbiota analysis on the same day.

\section{Total Cholesterol Measurement}

Total cholesterol concentration in serum samples was spectrophotometrically measured using the commercially available kit (Cholesterol E kit, Asan Phamaceutical Co., Seoul, Korea).

\section{Intestinal Microflora}

Individual cecal contents were aseptically sampled and kept on ice until use. Cecal contents were then subjected to serial $10-$ fold $(\mathrm{w} / \mathrm{v})$ dilution with ice-cold PBS. Total microbes were counted after grown on total plate agar (Becton Dixon, Franklin Lakes, NJ, USA), lactic acid bacteria on MRS agar (Becton Dixon), and total coli forms on MacConkay agar (Becton Dixon) at $37^{\circ} \mathrm{C}$ for $24 \mathrm{~h}$. The results were expressed as log base 10 colony-forming unit (cfu) per gram of cecal contents.

\section{Measurement of Malondialdehyde (MDA) in Leg Meat MDA Standard Curve}

A small quantity $(73.2 \mathrm{mg})$ of 1,1,3,3-tetra-ethoxypropane was weighed in a test tube, added with $10 \mathrm{ml} 0.1 \mathrm{~N} \mathrm{HCl}$ and immersed into a boiling water bath for $5 \mathrm{~min}$. The test tube was then immediately cooled down under running tap water, diluted to reach $100 \mathrm{~m} l$ with distilled water and used as a stock solution $(239 \mu \mathrm{g} / \mathrm{m} l)$. The stock solution was used to make serial dilutions which were then measured at $532 \mathrm{~nm}$ with UV-visible spectrophotometer (Beckman DU-530, Beckman Counter, Inc., Fullerton, CA, USA). Standard curve was generated and used to calculate unknown samples as described elsewhere (Botsoglou et al., 1994).

\section{MDA Measurement}

MDA levels in thigh meats were analyzed as described elsewhere (Botsoglou et al., 2002) with minor modifications. In brief, samples that had been stored at $-20^{\circ} \mathrm{C}$ were thawed at $4^{\circ} \mathrm{C}$ and used for analysis. Initially, 2 gram samples were 
Table 1. The ingredient and composition of the diet

\begin{tabular}{|c|c|c|}
\hline Ingredients & Starter (1-21 days) & Finisher (21-35 days) \\
\hline Yellow corn, $\mathrm{g}$ & 569.3 & 538.2 \\
\hline Wheat flour, $g$ & 30.6 & 31.0 \\
\hline Rice polishing, $\mathrm{g}$ & 20.0 & 20.0 \\
\hline Soybean meal, $\mathrm{g}$ & 152.8 & 145.4 \\
\hline Rapeseed meal, g & 30 & 45.0 \\
\hline Corn gluten meal $(60 \%), \mathrm{g}$ & 54.6 & 62.2 \\
\hline Distillers grain (CP 28\%), g & - & 50.0 \\
\hline Dehulled soybean meal (46\%), $\mathrm{g}$ & 50 & - \\
\hline Fish meal $(50 \%), \mathrm{g}$ & 28 & 28.0 \\
\hline Animal fat, $\mathrm{g}$ & 30 & 37.4 \\
\hline Limestone, $\mathrm{g}$ & 8.2 & 10.8 \\
\hline DL-methionine (99\%), g & 1.8 & 1.3 \\
\hline L-lysine $\mathrm{HCl}(78 \%), \mathrm{g}$ & 2.8 & - \\
\hline Lysine (liquid) (24\%), g & - & 10.2 \\
\hline Vitamin mineral mixture, $g$ & 2.6 & 2.6 \\
\hline $\mathrm{NaHCO}_{3}, \mathrm{~g}$ & 1.0 & - \\
\hline Threonine (99\%), g & 0.5 & 1.0 \\
\hline Salt, $\mathrm{g}$ & 3.0 & 3.0 \\
\hline Choline $\mathrm{Cl}, \mathrm{g}$ & 0.9 & 1.2 \\
\hline Dicalcium phosphate, $\mathrm{g}$ & 13.9 & 12.7 \\
\hline Total, g & 1000 & 1000 \\
\hline \multicolumn{3}{|l|}{ Calculated values } \\
\hline TMEn, kcal/kg & 3100 & 3100 \\
\hline Crude protein & 20.5 & 20.0 \\
\hline $\mathrm{Ca}, \%$ & 0.9 & 1.0 \\
\hline Available P, \% & 0.4 & 0.4 \\
\hline Lysine, \% & 1.2 & 1.1 \\
\hline Total TSAA, \% & 0.9 & 0.9 \\
\hline
\end{tabular}

Provided per kg of diet: vitamin A, $18000 \mathrm{IU}$; vitamin $\mathrm{D}_{3}, 3750 \mathrm{IU}$; vitamin E, $30 \mathrm{IU}$; vitamin $\mathrm{K}_{3}, 2.7 \mathrm{mg}$; vitamin $\mathrm{B}_{1}, 3.0 \mathrm{mg}$; vitamin $\mathrm{B}_{2}, 9.0 \mathrm{mg}$; vitamin $\mathrm{B}_{6}, 4.5 \mathrm{mg}$; vitamin $\mathrm{B}_{12}, 30.0 \mathrm{mg}$; niacin, $37.5 \mathrm{mg}$; pantothenic acid, $15 \mathrm{mg}$; folic acid, $1.5 \mathrm{mg}$; biotin, $0.07 \mathrm{mg}$; Fe, $75.0 \mathrm{mg}$; Zn, $97.5 \mathrm{mg}$; Mn, $97.5 \mathrm{mg}$; Cu, $7.5 \mathrm{mg}$; I, $1.5 \mathrm{mg}$; Se, $0.2 \mathrm{mg}$.

weighed into a $50 \mathrm{~m} l$ centrifuge tube, followed by $5 \mathrm{ml} 0.8 \%$ butylated hydroxytoluene (BHT) (dissolved in hexane) and 8 $\mathrm{m} l 5 \%$ trichloroacetate (dissolved in distilled water). The mixture was then mechanically homogenized for $30 \mathrm{~s}$ and centrifuged (Mage 210, Hanil, Korea) at 3,000 $\mathrm{g}$ for $5 \mathrm{~min}$. The bottom aqueous layer was carefully filtered (Whatman \#1) and made to reach $10 \mathrm{~m} l$ with $5 \%$ trichloroacetate. A 3 $\mathrm{m} l$ aliquot was transferred to $10 \mathrm{~m} l$ screw-capped tube and added with $0.8 \mathrm{~m} l$ 2-thiobarbituric acid (dissolved in distilled water). Following incubation at $70^{\circ} \mathrm{C}$ for $30 \mathrm{~min}$ with gentle shaking, the tube was cooled in ice-cold bath for $7 \mathrm{~min}$ and kept at room temperature for another $45 \mathrm{~min}$. The reaction mixture was measured at $532 \mathrm{~nm}$ using UV-visible spectrophotometer. All assays were repeated twice.

\section{Statistical Analysis}

Pen was considered as an experimental unit. All data were analyzed by analysis of variance using the General Linear Model procedure of SAS program (SAS, 1999). Differences between means were analyzed using Duncan's multiple range test. A statistical significance was preset at $P<0.05$ unless otherwise stated.

\section{Results}

\section{Growth Performance}

Final BW and overall BW gain were significantly increased $(P<0.05)$ in all treated groups compared with control group (Table 2). BW gain, feed intake and FCR at days 1-21 were not altered by any of treatments. At days 22-35, broiler chickens fed diets containing either AGP, SGV20 or SGV50 had greater BW gain compared with the control dietfed chickens. At days 22-35, broiler chickens on a diet added with SGV50 consumed more feed compared with the control group. However, dietary AGP or SGV20 failed to affect feed intake compared with the control chickens. FCR was significantly low $(P<0.05)$ in all treated groups compared with the control group, especially the diets on AGP and SGV20 groups being more efficiently utilized.

Relative Organ, Abdominal Fat and Edible Meat Weights Per $100 \mathrm{~g} \mathrm{BW}$

At day 35, relative weight of organs (i.e., spleen and Bursa of Fabricius), abdominal fat, and leg and breast muscles when expressed as $100 \mathrm{~g} \mathrm{BW}$ were not affected $(P>0.05)$ by any of treatments (Table 3 ). 
Table 2. Effect of sanguinarine on growth performance in broiler chickens ${ }^{1}$

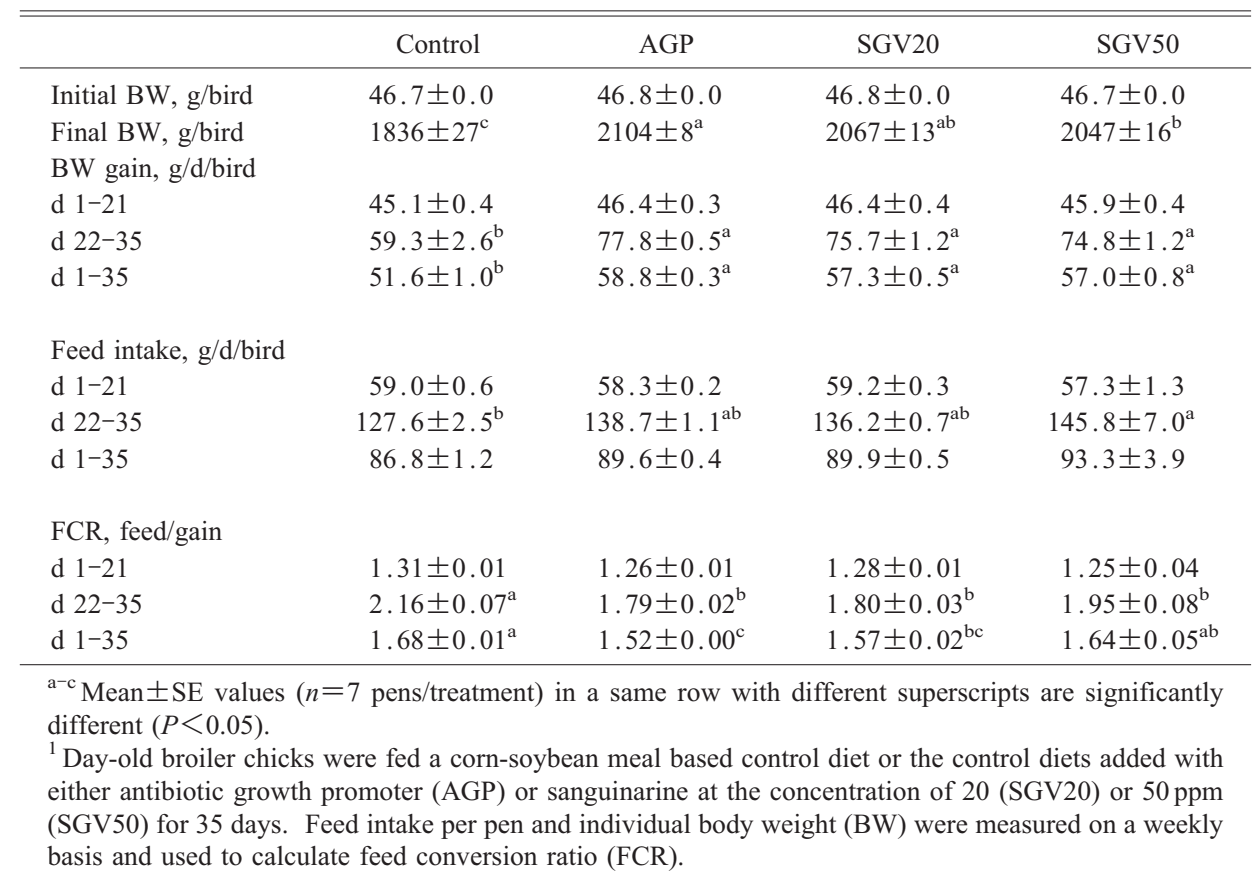

Table 3. Effect of sanguinarine on the relative weights of spleen, bursa of Fabricius, abdominal fats, leg and breast muscles in broiler chicken ${ }^{1}$

\begin{tabular}{lcccc}
\hline \hline & Control & AGP & SGV20 & SGV50 \\
\hline Spleen $^{2}$ & $0.12 \pm 0.01^{3}$ & $0.10 \pm 0.01$ & $0.13 \pm 0.02$ & $0.13 \pm 0.01$ \\
Bursa of Fabricius $^{2}$ & $0.17 \pm 0.01$ & $0.20 \pm 0.03$ & $0.23 \pm 0.02$ & $0.19 \pm 0.03$ \\
Abdominal fat $^{2}$ & $1.62 \pm 0.08$ & $1.39 \pm 0.07$ & $1.51 \pm 0.09$ & $1.44 \pm 0.08$ \\
Leg muscle $^{2}$ & $9.38 \pm 0.12$ & $9.32 \pm 0.18$ & $9.41 \pm 0.19$ & $9.58 \pm 0.18$ \\
Breast muscle $^{2}$ & $8.64 \pm 0.20$ & $9.11 \pm 0.23$ & $8.96 \pm 0.20$ & $9.07 \pm 0.23$ \\
\hline
\end{tabular}

\footnotetext{
${ }^{1}$ Day-old broiler chicks were fed a corn-soybean meal based control diet or the control diets added with either antibiotic growth promoter (AGP) or sanguinarine at the concentration of 20 (SGV20) or $50 \mathrm{ppm}$ (SGV50) for 35 days. At the end of the experiment, organs, abdominal fat, and leg and breast meats per chicken ( 7 chickens per pen, 7 pens per treatment) were weighed and used to calculate relative weight.

${ }^{2}$ Values are expressed as relative weight (g per $\left.100 \mathrm{~g} \mathrm{BW}\right)$

${ }^{3}$ Values are expressed as mean $( \pm \mathrm{SE})$.
}

\section{Relative Weight and Length of Small Intestine}

At day 35, relative jejunal weight was significantly lowered $(P<0.05)$ in SGV20 or SGV50 groups compared with the control group (Table 4). Dietary AGP failed to affect intestinal weight or length albeit that it marginally lowered $(P$ $>0.05)$ the relative jejunal weight and slightly increased $(P$ $>0.05)$ jejunal or ileal length in broiler chickens compared with the control group. Relative weight of duodenum or ileum was not altered by any of dietary treatments. Relative intestinal length per $100 \mathrm{~g} \mathrm{BW}$ tended to be increased when SGV was added into the control diet at the level of 20 or 50 ppm. Especially, relative jejunal length was increased in the SGV20-fed chickens compared with the control diet-fed counterparts. In addition, chickens fed diets containing
SGV20 or SGV50 had longer ileum per $100 \mathrm{~g} \mathrm{BW}$ compared with the control chickens.

\section{Intestinal Microflora}

Total microbes and coli forms in cecal contents were not affected by any of dietary treatments (Table 5). On the other hand, SGV20 significantly increased $(P<0.05)$ cecal lactic acid bacteria compared with the control diet-fed chickens.

Total Cholesterol Levels in Serum and MDA Content in Leg Meat

Serum total cholesterol levels were significantly low $(P<$ $0.05)$ in SGV20- or SGV50-fed chickens compared with the control group (Table 6). MDA as an indicator of lipid peroxidation was measured in this experiment and found that dietary SGV at all inclusion levels used significantly lowered 
Table 4. Effect of sanguinarine on the relative weights of and length of small intestine of broiler chicken ${ }^{1}$

\begin{tabular}{lllll}
\hline \hline & \multicolumn{1}{c}{ Control } & \multicolumn{1}{c}{ AGP } & \multicolumn{1}{c}{ SGV20 } & \multicolumn{1}{c}{ SGV50 } \\
\hline Weight $^{2}$ & & & & \\
$\begin{array}{l}\text { Duodenum } \\
\text { Jejunum }\end{array}$ & $0.34 \pm 0.03$ & $0.32 \pm 0.02$ & $0.27 \pm 0.02$ & $0.30 \pm 0.01$ \\
Ileum & $0.67 \pm 0.05^{\mathrm{a}}$ & $0.62 \pm 0.03^{\mathrm{ab}}$ & $0.47 \pm 0.01^{\mathrm{c}}$ & $0.54 \pm 0.02^{\mathrm{bc}}$ \\
Length $^{3}$ & $0.55 \pm 0.04$ & $0.56 \pm 0.01$ & $0.47 \pm 0.04$ & $0.48 \pm 0.01$ \\
Duodenum & & & & \\
Jejunum & $1.13 \pm 0.03$ & $1.17 \pm 0.03$ & $1.24 \pm 0.02$ & $1.21 \pm 0.03$ \\
Ileum & $3.06 \pm 0.10^{\mathrm{b}}$ & $3.21 \pm 0.11^{\mathrm{ab}}$ & $3.50 \pm 0.08^{\mathrm{a}}$ & $3.36 \pm 0.10^{\mathrm{ab}}$ \\
\hline
\end{tabular}

${ }^{\mathrm{a}-\mathrm{c}}$ Mean \pm SE values $(n=7 /$ treatment $)$ in a same row with different superscripts are significantly different $(P<0.05)$.

${ }^{1}$ Day-old broiler chicks were fed a corn-soybean meal based control diet or the control diets added with either antibiotic growth promoter (AGP) or sanguinarine at the concentration of 20 (SGV20) or $50 \mathrm{ppm}$ (SGV50) for 35 days. At the end of the experiment, individual small intestine per chicken ( 7 chickens per pen, 7 pens per treatment) was excised and relative weight and length were recorded.

${ }^{2}$ Values are expressed as relative weight (g per $\left.100 \mathrm{~g} \mathrm{BW}\right)$.

${ }^{3}$ Values are expressed as relative length (cm per $\left.100 \mathrm{~g} \mathrm{BW}\right)$.

Table 5. Effect of sanguinarine on intestinal microflora in broiler chickens ${ }^{1}$

\begin{tabular}{lllll}
\hline \hline & \multicolumn{1}{c}{ Control } & \multicolumn{1}{c}{ AGP } & \multicolumn{1}{c}{ SGV20 } & \multicolumn{1}{c}{ SGV50 } \\
\hline Total microbes, cfu/g & $6.06 \pm 0.23$ & $5.83 \pm 0.21$ & $6.17 \pm 0.24$ & $5.63 \pm 0.10$ \\
Coli forms, cfu/g & $5.77 \pm 0.21$ & $5.27 \pm 0.18$ & $5.46 \pm 0.22$ & $5.39 \pm 0.47$ \\
Lactic acid bacteria, cfu/g & $6.01 \pm 0.20^{\mathrm{b}}$ & $6.01 \pm 0.17^{\mathrm{b}}$ & $6.62 \pm 0.09^{\mathrm{a}}$ & $6.24 \pm 0.03^{\mathrm{ab}}$ \\
\hline
\end{tabular}

${ }^{\mathrm{a}-\mathrm{c}}$ Mean \pm SE values $(n=7 /$ treatment) in a same row with different superscripts are significantly different $(P<0.05)$.

${ }^{1}$ Day-old broiler chicks were fed a corn-soybean meal based control diet or the control diets added with either antibiotic growth promoter (AGP) or sanguinarine at the concentration of 20 (SGV20) or $50 \mathrm{ppm}$ (SGV50) for 35 days. At the end of the experiment, individual cecal content per chicken ( 7 chickens per pen, 7 replicates per treatment) was aseptically sampled for selected microbiota measurement.

Table 6. Effect of sanguinarine on serum cholesterol level and malondialdehyde content of leg muscle in broiler chicken ${ }^{1}$

\begin{tabular}{lcrrr}
\hline \hline & Control & AGP & SGV20 & \multicolumn{1}{c}{ SGV50 } \\
\hline Total cholesterol, $\mathrm{mg} / \mathrm{d} l$ & $144.9 \pm 1.1^{\mathrm{a}}$ & $136.0 \pm 5.3^{\mathrm{ab}}$ & $128.2 \pm 4.5^{\mathrm{bc}}$ & $117.0 \pm 6.1^{\mathrm{c}}$ \\
Malondialdehyde, $\mu \mathrm{g} / \mathrm{g}$ & $0.19 \pm 0.01^{\mathrm{a}}$ & $0.20 \pm 0.03^{\mathrm{a}}$ & $0.12 \pm 0.02^{\mathrm{b}}$ & $0.13 \pm 0.01^{\mathrm{b}}$ \\
\hline
\end{tabular}

${ }^{\mathrm{a}^{-\mathrm{c}}}$ Mean \pm SE values in a same row with different superscripts are significantly different $(P<0.05)$.

${ }^{1}$ Day-old broiler chicks were fed a corn-soybean meal based control diet or the control diets added with either antibiotic growth promoter (AGP) or sanguinarine at the concentration of 20 (SGV20) or $50 \mathrm{ppm}$ (SGV50) for 35 days. At the end of the experiment, blood and thigh meats per chicken were randomly sampled from 7 chickens per pen ( 7 pens per treatment) and used for measurement of cholesterol and malondialdehyde levels.

$(P<0.05)$ MDA levels in leg meats compared with those seen in the control group (Table 6). On the other hand, dietary AGP did not affect MDA levels.

\section{Discussion}

The present experiment was conducted to evaluate the novel plant-derived $\mathrm{SGV}$ as an alternative to antibiotic growth promoters (AGPs) in broiler chickens. In summary,
BW gain increased while feed conversion ratio (FCR) decreased in AGP- or SGV-treated chickens compared with the control chickens. SGV-fed chickens had decreased relative jejunal weight, but increased relative jejunal or ileal length compared with the control group. In addition, cecal lactic acid bacteria were significantly higher in broiler chickens fed a SGV-supplemented diet compared with those fed on the control diet. Finally, dietary SGV significantly 
lowered total cholesterol level in blood samples and MDA concentrations in thigh meats compared with the control group. It is clear from this study that dietary sanguinarine stimulates growth and exhibits various biological activities in broiler chickens of which properties lends its feasibility as the novel alternative to AGPs in poultry.

In this study, dietary AGP and SGV did not affect growth performance of broiler chickens at days 1-21, but significantly increased BW in broiler chickens at days $22-35$ or overall 1-35 days. At this stage, clear explanation on why AGP or SGV did not effect on body weight at early days of broiler chicken is not readily available. It is however of note that the growth-enhancing effect associated with the improvement of FCR is prominent at later days of life in broiler chickens. Feed intake was not affected by the treatments except for the SGV50-fed chickens which significantly consumed more at days 22-35 compared with the control group. Thus, it is likely that growth enhancing effect seen in this study is in part associated with the greater feed efficiency offered by AGP or SGV. In line with our result, dietary SGV has been known to increase BW of chickens, the effect being apparent at 21 days (Vieira et al., 2008a, b).

Dietary SGV lowered relative intestinal weight but increased relative intestinal length per $100 \mathrm{~g} \mathrm{BW}$. AGP did not affect intestinal morphology although it tended to increase relative intestinal length and to decrease the relative intestinal weight. Thus, it is likely that SGV-mediated increase in growth performance as shown in this study would be the consequence of altered gut morphology (e.g., thinning the intestine), thus facilitating efficient nutrient absorption. Indeed, it is well-known that dietary additives with antibiotic activity have been reported to affect small intestinal morphology, thereby leading to better nutrient digestion and absorption (Jukes et al., 1956; Hill et al., 1957; Humphrey et al., 2002).

Among cecal microflora measured, lactic acid bacteria were significantly increased $(P<0.05)$ by dietary SGV, but not by AGP. Total coli forms marginally lowered $(P>0.05)$ in all treated groups by more than $5 \%$ compared with the control group. The antibacterial activity by SGV has been reported in vitro (Herrera-Mata et al., 2002) and addition of SGV to broilers' diet lowered cecal fermentation as manifested by low levels of total short-fatty acid concentration (Jankowski et al., 2009). Similarly, Yakhkeshi et al. (2011) reported that dietary SGV increased lactic acid bacteria in ileal and cecal contents of broiler chickens at days 21 but this effect was disappeared at day 42. In addition, total coliforms in ileal and cecal contents were not altered by dietary SGV at days 21 and 42 (Yakhkeshi et al., 2011). It seems that dietary SGV favorably increased cecal lactic acid bacteria thus balancing gut microflora which otherwise may lead to lower growth performance. However, a question may arise whether simply increase in lactic acid bacteria is always beneficial to chickens. Further study on gut microbiota profile using molecular tools at the strain levels may help us understand its role in poultry nutrition and poultry health.

There is an indication that various plant-derived compo- nents may have hypocholesterolemic effect in broiler chickens (Lee et al., 2003), which prompted us to measure cholesterol concentrations in this study. As expected, we clearly observed the SGV-mediated hypocholesterolemic effect in broiler chickens. Earlier, conflicting results by SGV on cholesterol levels have been reported. For example, it is reported that SGV marginally lowered cholesterol in broiler chickens (Yakhkeshi et al., 2011) and pigs (Gudev et al., 2004). In contrast, Jankowski et al. (2009) reported a marginal $12 \%$ increase $(P=0.07)$ by dietary SGV in total cholesterol concentration compared with the control chickens. However, the underlying hypocholesterolemic mechanism(s) is not readily available at this stage which needs to be addressed.

Meat quality was assessed by monitoring MDA levels in leg meats of broiler chickens. It is often observed that various herbs and spices exhibited in vivo antioxidant property in broiler chickens (Botsogou et al., 2003; Rababah et al., 2006; Keokamnerd et al., 2008; Kim et al., 2009). In this study, dietary SGV at the level of 20 or $50 \mathrm{ppm}$ significantly lowered MDA concentrations of thigh meats in broiler chickens. However, dietary AGP did not exhibit antioxidant effect in broiler chickens. It is clear from this study that SGV vs. AGP exhibited more systemic biological properties which further lend its advantage over AGP use in broiler chickens. At this stage, question may arise as to how SGV exhibits the antioxidative effect in broiler chickens. The underlying mechanism on the SGV-mediated decrease in MDA concentration would be either its direct protective effect on meat oxidation or via the altered fatty acid composition. The former mechanism is however not likely to occur as SGV is reported to be excreted without being absorbed via intestine (Zdarilova et al., 2008). It is thus more likely that SGV-fed chickens may contain less oxidative fatty acids. Indeed, a previous study (Juskiewicz et al., 2011) showing that dietary SGV altered the fatty acid compositions of breast meats in broiler chickens supports our latter statement on the putative mechanism for its antioxidant property. In any event, further study is needed to clarify the effect of SGV on lipid metabolism and its antioxidant activity in broiler chickens.

In this study, we did observe various biological effects by SGV in addition to its growth enhancing property which is of practical importance to poultry industry. SGV is mainly composed of sanguinarine, a quaternary benzo[c]phenanthridine alkaloid (Dvorak and Simanek, 2007), as active component which derived from the powered stems, leaves, capsules and seeds of Macleaya cordata. In traditional Chinese medicine, the aerial part of $M$. cordata has long been used for its analgesic, anti-inflammatory properties, antimicrobial and immunomodulatory activities (Simanek et al., 2003; Dvorak et al., 2006; Niu et al., 2012). Of practical importance, SGV stimulates the secretion of enzymes in the intestine (Franz et al., 2005), which is often regarded as typical characteristic of herbs and spices (Lee et al., 2003). It has been reported that dietary SGV is not metabolized into potentially harmful metabolite (e.g., benz[c]acridine) and is 
excreted without being absorbed through the small intestine (Zdarilova et al., 2008). Collectively, it is likely that the primary action mechanism by SGV is via intestine. Indeed, the latter statement supports our finding on the SGVmediated alteration in relative small intestine per $100 \mathrm{~g} \mathrm{BW}$ and gut microbiota in broiler chickens, which could lead to efficient nutrient partitioning into growth.

In conclusion, the present study revealed that dietary SGV (sanguinarine as an active component) significantly increased BW gain and improved FCR in broiler chickens. In addition, it altered gut structure, balanced gut microbiota, and lowered serum total cholesterol levels and MDA in thigh meats of 35-d-old broiler chickens. Our study suggests that dietary SGV can favorably use as an alternative to AGP in poultry feeding. Further study is warranted to see whether dietary SGV can exhibit beneficial preventive effect on economically important diseases such as Clostridium performance or Eimeria spp. in broiler chickens. Indeed, recent study by Pickler et al. (2013) who reported that sanguinarine effectively controlled Salmonella Enteritis in broiler chickens indicates that dietary sanguinarine could play an important role in reducing economically important enteric diseases.

\section{Acknowledgments}

This paper was supported by KonKuk University in 2014. We thank In-Sook An in the Poultry Science Laboratory, Department of Animal Science and Technology, College of Animal Bioscience and Technology, KonKuk University for the technical assistance.

\section{References}

Botsoglou NA, Fletouris DJ, Papageorgiou GE, Vassilopoulos VN, Mantis AJ and Trakatellis AG. Rapid, sensitive, and specific thiobarbituric acid method for measuring lipid peroxidation in animal tissue, food, and feedstuff samples. Journal of Agriculture and Food Chemistry, 42: 1931-1937. 1994.

Botsoglou NA, Florou-paneri P, Christaki E, Fletouris DJ and Spais AB. 2002. Effect of dietary oregano essential oil on performance of chickens and on iron-induced lipid oxidation of breast, thigh and abdominal fat tissues. British Poultry Science, 43: 223-230. 2002.

Dvorak Z, Kuban V, Klejdus B, Hlavac J, Vicar J, Ulrichova J and Simanek V. Quaternary benzo[c]phenanthridines sanguinarine and chelerythrine: A review of investigations from chemical and biological studies. Heterocycles, 68: 2403-2422. 2006.

Dvorak Z and Simanek V. Metabolism of sanguinarine: The fats and the myths. Current Drug Metabolism, 8: 173-176. 2007.

Franz C, Bauer R, Carle R, Tedesco D, Tubaro A and ZitterlEglseer K. Study on the assessment of plants/herb extracts and their naturally or synthetically produced components as "additives" for use in animal production. CFT/EFSA/FEEDAP/ 2005/01. http://www. efsa. europa. eu/de/supporting/doc/070828. pdf. Assessed at October 31, 2013.

Godfray HC, Beddington JR, Crute IR, Haddad L, Lawrence D, Muir JF, Pretty I, Robinson S, Thomas SM and Toulmin C. Food security: The challenge of feeding 9 billion people. Science, 327: 812-818. 2010.

Grashorn MA. Use of phytobiotics in broiler nutrition - an alter- native to infeed antibiotics? Journal of Animal and Feed Sciences, 19: 338-347. 2010.

Gudev D, Popova- Ralcheva S, Moneva P, Bonovska M, Valchev G and Valcheva A. Effect of supplemental Sangrovit on some biochemical indices and leukocytes phagocytic activity in growing pigs. Archiva Zootechnica, 7: 19-26. 2004.

Hashemi SR and Davoodi H. Phytogenics as new class of feed additive in poultry industry. Journal of Animal and Veterinary Advances, 9: 2295-2304. 2010.

Herrera-Mata H, Rosas-Romero A and Crescente O. Biological activity of Sanguinaria (Justica secunda) extracts. Pharmaceutical Biology, 40: 206-212. 2002.

Hill CH, Keeling AD and Kelly JW. Studies on the effect of antibiotics on the intestinal weights of chicks. Journal of Nutrition, 62: 255-267. 1957.

Humphrey BD, Huang $\mathrm{N}$ and Klasing KC. Rice expressing lactoferrin and lysozyme has antibiotic-like properties when fed to chicks. Journal of Nutrition, 132: 1214-1218. 2002.

Jankowski J, Zdunczyk Z, Juskiewicz J, Kozlowski K, Lecewicz A and Jeroch H. Gastrointestinal tract and metabolic response of broilers to diets with the Macleaya cordata alkaloid extract. Archiv Fur Geflugelkunde, 73: 95-101. 2009.

Jukes HG, Hill DC and Branion HD. Effect of feeding antibiotics on the intestinal tract of the chick. Poultry Science, 35: 716-723. 1956.

Justkiewicz J, Gruzauskas R, Zdunczyk Z, Semaskaite A, Jankowski J, Totilas Z, Jarule V, Sasyte V, Zdunczyk P, RaceviciuteStupeliene A and Svirmickas G. Effects of dietary addition of Macleaya cordata alkaloid extract on growth performance, caecal indices and breast meat fatty acids profile in male broilers. Journal of Animal Physiology and Animal Nutrition, 95: 171-178. 2011.

Keokamnerd T, Acton JC, Han IY and Dawson PL. Effect of commercial rosemary oleoresin preparations on ground chicken thigh meat quality packaged in a high-oxygen atmosphere. Poultry Science, 87: 170-179. 2008.

Kim YR, Lee BK, Kim JY, Kim JS, Lee WS, Lee SY, Kim EJ, Ahn BK and Kang CW. Effects of dietary locally growth herbs (Mentha piperascens, Rubus coreanus, Tagetes patula) on the growth performance and meat quality of broiler chickens. Korean Journal of Food Science and Technology, 29: 168177. 2009.

Lee KW, Everts H, Kappert HJ, Frehner M, Losa R and Beynen AC. Effects of dietary essential oil components on growth performance, digestive enzymes and lipid metabolism in female broiler chickens. British Poultry Science, 44: 450-457. 2003.

Lillehoj HS and Lee KW. Immune modulation of innate immunity as alternatives-to-antibiotics strategies to mitigate the use of drugs in poultry production. Poultry Science, 91: 1286-1291. 2012.

National Research Council. Nutrient requirement of poultry. $9^{\text {th }}$ ed. National Academy Press. Washington DC, USA. 1994.

Niu X, Fan T, Li W, Wing W and Huang H. The anti-inflammatory effects of sanguinarine and its modulation of inflammatory mediators from peritoneal macrophages. European Journal of Phamacology, 689: 262-269. 2012.

Pickler L, Beirao BCB, Ricardo RM, Hayashi M, Durau JF, Lourenco MC, Caron LF and Santin E. Effect of sanguinarine in drinking water on Salmonella control and the expression of immune cells in peripheral blood and intestinal mucosa of broilers. Journal of Applied Poultry Research, 22: 430-438. 2013. 
Rababah TM, Ereifej KI, Al-Mahasneh MA and Al-Rababah MA. Effect of plant extracts on physicochemical properties of chicken breast meat cooked using conventional electric oven or microwave. Poultry Science, 85: 148-154. 2006.

SAS. SAS user's guide. Statistics, Version 8, SAS Institute. Inc., Cary, NC, USA. 2002.

Simanek V, Vespalec R, Sedo A, Ulrichova J and Vicar J. Quaternary benzo[c]phenanthridine alkaloids - Biological activities. In: Chemical Probes in Biology. NATO Science Series II. Mathematics, Physics and Chemistry - 129 (Schneider MP Ed.). pp. 245-254. Kluwer Academic Publishers, Dordrecht. 2003.

Thomke S and Elwinger K. Growth promotants in feeding pigs and poultry. I. Growth and feed efficiency responses to antibiotic growth promotants. Annales de Zootechnie, 47: 85-97. 1998.

Vieira SL, Berres J, Reis RN, Oyarzabal OA, Coneglian JLB, Freitas DM, Pena JEM and Torres CA. Studies with sanguinarine like alkaloids as feed additive in broiler diets. Brazilian Journal of Poultry Science, 10: 67-71. 2008a.

Vieira SL, Oyarzabal OA, Freitas DM, Berres J, Pena JEM, Torres CA and Coneglian JLB. Performance of broilers fed diets supplemented with sanguinarine-like alkaloids and organic acid. Journal of Applied Poultry Research, 17: 128-133. 2008b.

Vrba J, Hrbac J, Ulrichova J and Modriansky M. Sanguinarine is a potent inhibitor of oxidative burst in DMSO-differentiated HL60 cells by a non-redox mechanism. Chemico-Biological Interactions, 147: 35-47. 2004.

Windisch W, Schele K, Plitzner C and Kroismayr A. Use of phytogenic products as feed additives for swine and poultry. Journal of Animal Science, 86: E140-E148. 2008.

Yakhkeshi S, Rahimi S and Gharib Naseri K. The effects of comparison of herbal extracts, antibiotics, probiotics and organic acid on serum lipids, immune response, GIT microbial population, intestinal morphology and performance of broilers. Journal of Medicinal Plants, 10: 80-95. 2011.

Yang Y, Iji PA and Choct M. Dietary modulation of gut microflora in broiler chickens: a review of the role of six kinds of alternatives to in-feed antibiotics. World's Poultry Science Journal, 65: 97-114. 2009.

Zdarilova A, Vrublova E, Vostalova J, Klejdus B, Stejskal D, Proskova J, Kosina P, Svobodova A, Vecera R, Hrbac J, Cernochova D, Vicar J, Ulrichova J and Simanek V. Natural feed additive of Macleaya cordata: safety assessment in rats a 90-day feeding experiment. Food and Chemical Toxicology, 46: 3721-3726. 2008. 